This document is the accepted manuscript version of the following article: Bugaev, A. L., Zabilskiy, M., Skorynina, A. A., Usoltsev, O. A., Soldatov, A. V., \& van Bokhoven, J. (2020). In situ formation of surface and bulk oxides in smal1 palladium nanoparticles. Chemical Communications. https://doi.org/10.1039/D0CC05050D

\title{
COMMUNICATION
}

\section{In situ formation of surface and bulk oxides in small palladium nanoparticles}

Received 00th January 20xx, Accepted 00th January 20xx
Aram L. Bugaev, ${ }^{* a, b}$ Maxim Zabilskiy, ${ }^{c}$ Alina A. Skorynina, ${ }^{a}$ Oleg A. Usoltsev, ${ }^{a}$ Alexander V. Soldatov, ${ }^{a}$ Jeroen A. van Bokhoven ${ }^{c, d}$

DOI: $10.1039 / x 0 x \times 00000 x$

Evolution of surface and bulk palladium oxides in supported palladium nanoparticles was followed in situ by X-ray absorption spectroscopy. The surface oxide was found to be easily reducible in hydrogen at room temperature, while removal of bulk oxide required heating in hydrogen above $100{ }^{\circ} \mathrm{C}$. We also found that the co-presence of hydrogen and oxygen favours stronger oxidation of palladium particles compared to pure oxygen.

Palladium-based materials are extensively investigated as catalysts for a wide range of important industrial reactions, such as methane combustion ${ }^{1-4}$ and selective oxidation of alcohols..$^{5-}$ 7 Palladium oxide is generally considered to be the actual catalytic species in many of these reactions, however, the activity of metallic palladium or core-shell combinations of $\mathrm{Pd}$ and $\mathrm{PdO}$ were also reported. ${ }^{8-10} \mathrm{~A}$ number of previous studies highlighted the importance of in situ detection of palladium oxides and their distribution in the bulk and at the surface of palladium particles to highlight the actual active phase in catalytic oxidation reactions. ${ }^{5,6}$

Oxidation and reduction of palladium phases are very complex process often associated with the formation of core-shell structures. $^{11,12}$ Generally, it was shown that the extent of oxidation increases with decreasing particle size and crystallinity of palladium. ${ }^{8}$ The surface oxide layer can be formed even at $200 \mathrm{~K}$, while the bulk oxidation begins at significantly higher temperatures $-473 \mathrm{~K}\left(200{ }^{\circ} \mathrm{C}\right)$. The latter process starts from the formation of an amorphous oxide layer which then slowly transforms into crystalline PdO. ${ }^{13,}{ }^{14}$ Such stability of core-shell structures with surface palladium oxide layer can be attributed to the surface tension of PdO, which is lower than that of metallic Pd. ${ }^{15}$ This makes the model with

a. The Smart Materials Research Institute, Southern Federal University, Sladkova 178/24, 344090, Rostov-on-Don, Russia.Email: abugaev@sfedu.ru

b. Southern Scientific Centre, Russian Academy of Sciences, Chekhova 41, 344006 Rostov-on-Don, Russia Address here.

Laboratory for Catalysis and Sustainable Chemistry, Paul Scherrer Institute, 5232 Villigen, Switzerland

d. Institute for Chemical and Bioengineering, ETH Zurich, Vladimir-Prelog-Weg 1, 8093 Zurich, Switzerland

† Footnotes relating to the title and/or authors should appear here.

Electronic Supplementary Information (ESI) available: [details of any supplementary information available should be included here]. See DOI: 10.1039/x0xx00000x metallic core and PdO shell energetically more favorable. Formation of such structures was observed also during reduction of palladium oxide phase. In particular, thermal reduction was associated with a gradual growth of the metallic core inside PdO particles. ${ }^{16}$ However, in presence of hydrogen the reduction starts from the formation of metallic Pd surface which progressively grows towards the bulk. ${ }^{11}$ It was reported, that the surface palladium oxide can be fully reduced in hydrogen at $150{ }^{\circ} \mathrm{C}$, while about $50 \%$ of the bulk structure remained oxidized, which was explained by slow diffusivity of oxygen in palladium. ${ }^{12}$

Probing the local atomic and electronic structure around the element of interest using X-ray absorption spectroscopy (XAS), was successfully applied to discriminate metallic palladium and palladium oxide phases. Extended X-ray absorption fine structure (EXAFS) spectra contain information about the interatomic distances and coordination numbers $(\mathrm{CNs})^{17}$ and can directly probe the $\mathrm{Pd}-\mathrm{Pd}$ and $\mathrm{Pd}-\mathrm{O}$ coordination in the bulk palladium oxide phases. In addition, $\mathrm{X}$-ray absorption near-edge structure (XANES) spectroscopy probes the unoccupied density of states being therefore sensitive to the changes in the electronic structure due to the chemisorption of the reactive species at the surface of the catalyst and introduction of light impurities $(\mathrm{H}, \mathrm{C}, \mathrm{O})$ into the palladium lattice, which has a minor effect on EXAFS. ${ }^{18-21}$

Here, we apply combined Pd $K$-edge EXAFS and XANES analysis to follow the restructuring of the palladium lattice and, respectively, the relative ratio of $\mathrm{Pd}^{2+} / \mathrm{Pd}^{0}$ in small palladium nanoparticles exploiting catalytic oxidation of hydrogen as a model reaction. Although XAS is a bulk sensitive technique, the large fraction of atoms at the surface of nanometer-sized particles provides sufficient sensitivity and enables detecting both bulk and surface species. Particularly, in the nanoparticles below $3 \mathrm{~nm}$, more than half of atoms is located at the surface (where catalytic reaction occurs), which can be successfully monitored by XAS to investigate catalytic pathways. For this reason, we aimed to achieve high level of palladium dispersion over $\gamma$-alumina support and to investigate this material in situ under hydrogen oxidation reaction conditions. 


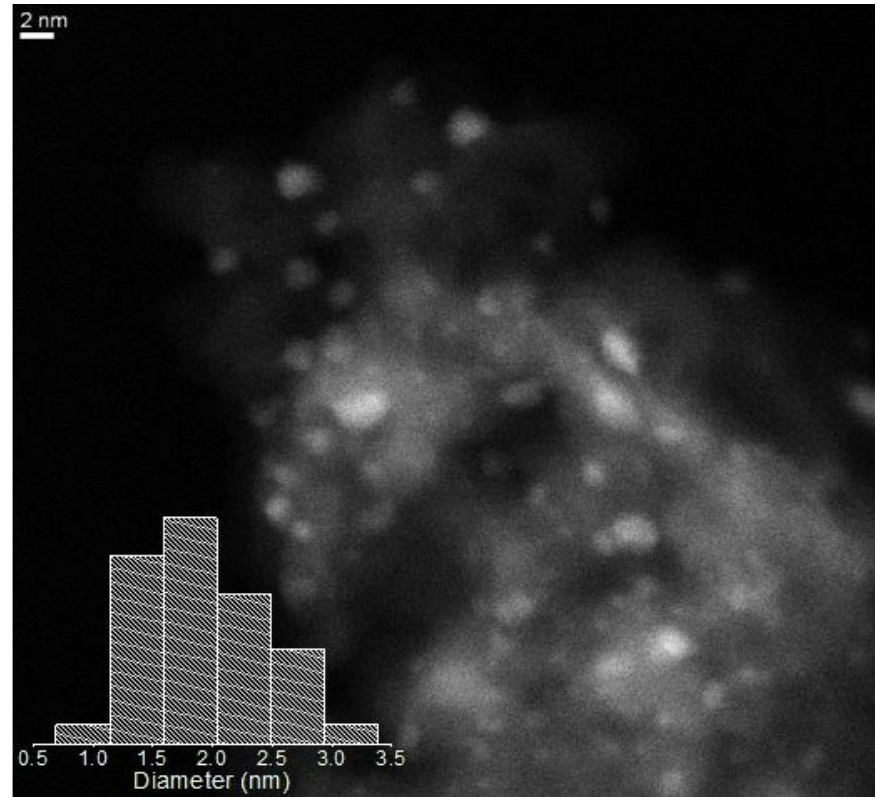

Fig. 1. The HAADF-STEM micrograph of $\mathrm{Pd} / \mathrm{Al}_{2} \mathrm{O}_{3}$ sample as well as palladium particle size distribution (insert).

The prepared $\mathrm{Pd} / \mathrm{Al}_{2} \mathrm{O}_{3}$ catalyst as well as $\mathrm{\gamma}$-alumina support were thoroughly characterized by variety of physico-chemical methods (Table S1). Due to the high BET specific surface area of utilized $\gamma$-alumina support (Fig. S3) and the applied gentle thermal treatment during preparation steps of $\mathrm{Pd} / \mathrm{Al}_{2} \mathrm{O}_{3}$ synthesis, we have achieved high level of palladium dispersion. Detailed analysis of XRD patterns of $\gamma$-alumina support and $\mathrm{Pd} / \mathrm{Al}_{2} \mathrm{O}_{3}$ catalyst (Fig. S2) revealed the absence of the reflections related to any palladium phase, which can be also attributed to the nanometric dimensions of the palladium particles. Based on the results of $\mathrm{H}_{2}$ chemisorption (Fig. S4), the determined palladium dispersion (i.e. the fraction of surface atoms) is $48 \%$. The average particle size estimated using the difference method corresponds to $2.3 \mathrm{~nm}$ (based on the assumption that palladium nanoparticles exhibit a semispherical geometry). STEM analysis (Fig. 1, Fig. S1) revealed the formation of palladium nanoparticles with mean nanoparticle size of $1.9 \pm 0.4 \mathrm{~nm}$.

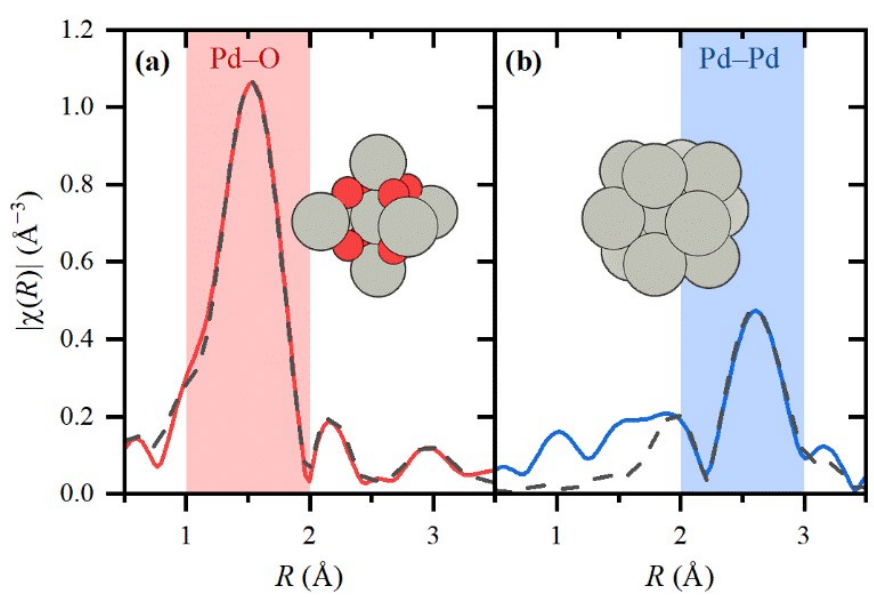

Fig. 2. Experimental FT-EXAFS (solid colored lines) and best fits (dashed grey lines) for the catalyst before (a) and after (b) reduction in hydrogen.
XAS data show that the initial structure of the catalyste after

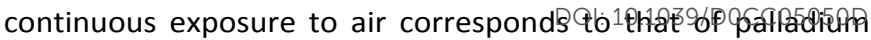
oxide. The EXAFS fitting using the tetragonal palladium (II) oxide phase (Fig.2Figa, Table S2) gives an excellent agreement with the experimental data. The cluster size $D=(0.5 \pm 0.2) \mathrm{nm}$, determined based on $\mathrm{CNs}$, confirms the formation of small palladium clusters. The lower quantitative value compared to STEM and BET results may be explained by (i) structural distortion and deviation from an ideal spherical shape and tetragonal crystal structure (ii) correlation between $D$ and Debye-Waller parameter $\left(\sigma^{2}\right)$, and (iii) the fact that the smallest particles may escape from STEM detection due to the worse contrast. Notably, the FT-EXAFS signal above $2 \AA$ is almost completely reduced compared to bulk palladium oxide and 2.6 $\mathrm{nm} \mathrm{PdO}$ nanoparticles (Figure S7b in ESI). After exposure to $\mathrm{H}_{2}$ at $125^{\circ} \mathrm{C}$ the sample was reduced to metallic palladium (Fig.2b, Table S2) with $R_{\text {Pd-Pd }}=2.75 \pm 0.01 \AA$. Although significantly reduced in magnitude, all observed peaks in FT-EXAFS correspond to those in the data for palladium foil and differently sized palladium NPs (Figure S7a), 22, 23 indicating the fcc-like structure in the reduced sample. The obtained first shell $\mathrm{CN}=6.3 \pm 0.9$ is lower than $\mathrm{CN}=12$ of bulk palladium and corresponds to the particle size of ca. $1 \mathrm{~nm}$ assuming their ideal spherical shape. However, bigger particles with defects and non-spherical shape may also result in the similar values of $\mathrm{CN}{ }^{6}$ The remaining unfitted background below $2 \AA$ (Fig.2Figb) originates from the interaction of surface palladium atoms with the support, whose contribution to the spectra is considerable due to the small particle size. ${ }^{23}$ XANES region before and after reduction is shown in Figure 3a. No evidence of hydride phase was observed according to the shaping of XANES ${ }^{18,20,21,24,25}$ in agreement with phase diagram for nanometric palladium particles. ${ }^{21,} 26-28$

The experimental conditions which were then adopted are summarized in Fig. $3 \mathrm{~b}$ which also demonstrate the relative fraction of $\mathrm{Pd}^{2+}$ and $\mathrm{Pd}^{0}$ obtained by linear combination fitting of all experimental data using the spectra before and after reduction, respectively, which are shown in part (a) of the figure. The representative XANES and Fourier-transformed (FT) EXAFS spectra for each region are shown in Fig.3c-d.

After reduction at $125^{\circ} \mathrm{C}$, sample was exposed to oxygen $(3.3 \%$ in $\mathrm{He}$ ) and immediately cooled down to $50{ }^{\circ} \mathrm{C}$ (region 3). The partial oxidation was observed. However, the structure of the nanoparticles did not fully return to the palladium oxide state as in the as-prepared material. The corresponding XANES spectrum (Fig.3c) is an intermediate between the starting palladium oxide and reduced phase. The FT-EXAFS signal below $2 \AA$ is enhanced (Fig.3d) indicative of $\mathrm{Pd}-\mathrm{O}$ contribution, however, the dominant peak is the Pd-Pd one at ca. $2.5 \AA$ (phase-uncorrected) as in metallic palladium. Remarkably, these oxidic species gradually disappear already at $50{ }^{\circ} \mathrm{C}$ upon reduction in hydrogen (region 4 in Fig.3b-d).

Then, the sample was cooled to $30{ }^{\circ} \mathrm{C}$ and a catalytic mixture of $4.2 \% \mathrm{H}_{2} / 3.3 \% \mathrm{O}_{2} / \mathrm{He}$ was fed. Under reaction conditions, experimental XANES spectra became identical to the fully oxidized ones with almost complete removal of Pd-Pd contribution from EXAFS (region 5 in Fig.3b-d). Interestingly, the 
formed oxide species were stable in hydrogen at low temperatures (region 6) and were reduced only by heating in hydrogen to above $100{ }^{\circ} \mathrm{C}$ (region 7).

A simultaneous view on the evolution of both EXAFS and XANES spectra can provide the insights on the surface and bulk distribution of palladium oxides under the reaction conditions. LCA analysis of XANES data allowed us to determine the relative $\mathrm{Pd}^{2+} / \mathrm{Pd}^{0}$ ratio. The principle component analysis (PCA) showed that the dataset is indeed characterized by only two independent components (Figure S5), which is also supported by the isosbestic points in the spectra (Figure S6). This justifies the application of LCA with two components for this dataset. However, the similarity of $\mathrm{Pd}-\mathrm{O}, \mathrm{Pd}-\mathrm{OH}$ species in XANES (Figure S9, S10) may complicate the discrimination of these two species from the experimental data (i.e. both will be described by one $\mathrm{Pd}^{2+}$ component). Despite only two different components ( $\mathrm{Pd}^{0}$ and $\mathrm{Pd}^{2+}$ ) can be discriminated by XANES, different behavior of the species assigned to $\mathrm{Pd}^{2+}$ was observed. In particular, the initial structure (1), and the one formed under reaction conditions (5) were reduced only at temperatures above $100^{\circ} \mathrm{C}$, while the one formed upon small dose of oxygen (3) was reduced at $50{ }^{\circ} \mathrm{C}$. From general point of view, the easily reducible $\mathrm{Pd}^{2+}$ species can be assigned to surface oxide, while the one reduced at higher temperature is a bulk oxide.

FT-EXAFS spectra support this hypothesis. Indeed, the initial spectrum and the one formed under reaction conditions (spectra 1, 5-6 in Fig.3) are characterized by a clear $\mathrm{Pd}-\mathrm{O}$ peak around $1.5 \AA$ (phase-uncorrected) with much weaker ${ }_{A}$ signal

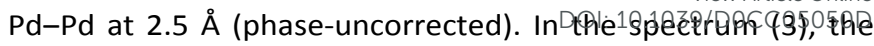
$\mathrm{Pd}-\mathrm{Pd}$ signal remains strong as in the spectrum of reduced palladium (2), which means that the overall framework of palladium is similar to the metallic state. At the same time, smooth background below $2 \AA$ (phase-uncorrected) can be explained by surface $\mathrm{Pd}-\mathrm{O}$ bonds, which are more disordered with the respect to bulk oxide to result in a well-defined peak in FT-EXAFS. Thus, under reaction conditions, stable bulk palladium oxide phase was observed, while in oxygen only surface one was formed within the studied time scale (ca. $1 \mathrm{~h}$ ) and oxygen concentration (3.3\%).

Formation of stronger oxide under reaction conditions can be explained by the local heat release due to exothermic hydrogen oxidation reaction evidenced in Fig. S13. From the other side, palladium is known to adsorb hydrogen forming palladium hydrides with increased Pd-Pd distances. ${ }^{18,}$ 26, 29-32 In presence of hydrogen, palladium structure becomes more "flexible" 33 which may facilitate the restructuring from metallic palladium to its oxide structure. It should be noted that, the range of achieved temperatures (Fig. S13) allows the formation of palladium hydrides. However, no significant increase of Pd-Pd distance was observed as can be expected for such small particles. $^{32}$ These ultra-small palladium particles also demonstrate much higher stability of oxide phase compared to bigger particles (ca. $3 \mathrm{~nm}$ ) which were reduced in hydrogen already at room temperature (Fig. S8).


Fig. 3. (a): XANES spectra before (red) and after (blue) reduction. (b): XANES LCA profiles obtained using the two spectra shown in panel (a). Representative XANES spectra and FT of EXAFS from each region of panel (b) are shown in panels (c) and (d), respectively. 
To summarize, we have performed in situ XAS study of ultrasmall palladium particles under various conditions including catalytic oxidation of hydrogen. Analysis of both XANES and EXAFS spectra allowed discrimination between surface and bulk oxide species. We found that only surface oxide is formed in presence of oxygen at temperatures below $125{ }^{\circ} \mathrm{C}$, which correlates with previous reports for bulk surfaces and supported palladium nanoparticles. The presence of hydrogen facilitates the complete transformation of the metallic palladium particles into bulk palladium oxide already at room temperature. The bulk oxide phase demonstrated stability up to $100{ }^{\circ} \mathrm{C}$ in hydrogen, while the surface oxide was readily removed at lower temperatures. The presence of hydrogen was crucial to form stable bulk oxides at low temperatures due to (i) additional heat realize during hydrogen oxidation and (ii) potential increase of the oxygen diffusion in the palladium hydride.

\section{Conflicts of interest}

There are no conflicts to declare.

\section{Acknowledgements}

The work was financially supported by the Russian Foundation for Basic Research (Grant \#19-32-60083 to A.L.B.). The authors acknowledge the ESRF for providing the beamtime at SwissNorwegian beamline (BM31) for XAS measurements. O.A.U and A.A.S. acknowledge the President's Grant of Russian Federation for Young Scientists MK-2554.2019.2 (Agreement No. 075-15-2019-1096) for travel support. We are indebted to Vladimir Dmitriev, Wouter van Beek and Dragos Stoian for their help during the experiment at BM31.

\section{Notes and references}

1 D. Ciuparu, M. R. Lyubovsky, E. Altman, L. D. Pfefferle and A. Datye, Cat. Rev. - Sci. Eng., 2002, 44, 593-649.

2 E. D. Goodman, A. A. Ye, A. Aitbekova, O. Mueller, A. R. Riscoe, T. Nguyen Taylor, A. S. Hoffman, A. Boubnov, K. C. Bustillo, M. Nachtegaal, S. R. Bare and M. Cargnello, J. Chem. Phys., 2019, 151, 154703.

3 R. J. Farrauto, M. C. Hobson, T. Kennelly and E. M. Waterman, Appl. Catal., A, 1992, 81, 227-237.

4 J. D. Grunwaldt, N. van Vegten and A. Baiker, Chem. Commun., 2007, DOI: 10.1039/b710222d, 4635-4637.

5 J. D. Grunwaldt, M. Caravati and A. Baiker, J. Phys. Chem. B, 2006, 110, 25586-25589.

6 E. Groppo, A. Lazzarini, M. Carosso, A. Bugaev, M. Manzoli, R. Pellegrini, C. Lamberti, D. Banerjee and A. Longo, ACS Catal., 2018, 8, 6870-6881.

7 H. Yang, S. Li, F. Feng, S. Ou, F. Li, M. Yang, K. Qian, J. Jin and J. Ma, ACS Sustainable Chemistry \& Engineering, 2019, 7, 14621-14628.

8 R. Hicks, J. Catal., 1990, 122, 295-306.

9 A. Hellman, A. Resta, N. M. Martin, J. Gustafson, A. Trinchero, P. A. Carlsson, O. Balmes, R. Felici, R. van Rijn, J. W. Frenken, J. N. Andersen, E. Lundgren and H. Gronbeck, J. Phys. Chem. Lett., 2012, 3, 678-682.
10 S. Oh, P. Mitchell and R. Siewert, J. Catal., 1991 132 287-301. DOl: 10.1039/DOCC05050D

11 S. C. Su, J. N. Carstens and A. T. Bell, J. Catal., 1998, 176, 125-135.

12 W. E. Moddeman, W. C. Bowling, D. C. Carter and D. R. Grove, Surf. Interf. Anal., 1988, 11, 317-326.

13 X. Guo, A. Hoffman and J. T. Yates, J. Chem. Phys., 1989, 90, 5787-5792.

14 J. M. Guiot, J. Appl. Phys., 1968, 39, 3509-3511.

15 S. H. Overbury, P. A. Bertrand and G. A. Somorjai, Chem. Rev., 1975, 75, 547-560.

16 E. H. Voogt, A. J. M. Mens, O. L. J. Gijzeman and J. W. Geus, Surf. Sci., 1996, 350, 21-31.

17 J. A. van Bokhoven and C. Lamberti, X-ray absorption and $X$-ray emission spectroscopy: theory and applications, Wiley \& Sons, Chichester, 2016.

18 A. L. Bugaev, A. A. Guda, A. Lazzarini, K. A. Lomachenko, E. Groppo, R. Pellegrini, A. Piovano, H. Emerich, A. V. Soldatov, L. A. Bugaev, V. P. Dmitriev, J. A. van Bokhoven and C. Lamberti, Catal. Today, 2017, 283, 119-126.

19 A. L. Bugaev, A. A. Guda, I. A. Pankin, E. Groppo, R. Pellegrini, A. Longo, A. V. Soldatov and C. Lamberti, Catal. Today, 2019, 336, 40-44.

20 A. L. Bugaev, O. A. Usoltsev, A. A. Guda, K. A. Lomachenko, I. A. Pankin, Y. V. Rusalev, H. Emerich, E. Groppo, R. Pellegrini, A. V. Soldatov, J. A. van Bokhoven and C. Lamberti, J. Phys. Chem. C, 2018, 122, 1202912037.

21 A. L. Bugaev, O. A. Usoltsev, A. Lazzarini, K. A. Lomachenko, A. A. Guda, R. Pellegrini, M. Carosso, J. G. Vitillo, E. Groppo, J. A. van Bokhoven, A. V. Soldatov and C. Lamberti, Faraday Discuss., 2018, 208, 187-205.

22 M. W. Tew, J. T. Miller and J. A. van Bokhoven, J. Phys. Chem. C, 2009, 113, 15140-15147.

23 V. V. Srabionyan, A. L. Bugaev, V. V. Pryadchenko, L. A. Avakyan, J. A. van Bokhoven and L. A. Bugaev, J. Phys. Chem. Solids, 2014, 75, 470-476.

24 A. L. Bugaev, V. V. Srabionyan, A. V. Soldatov, L. A. Bugaev and J. A. van Bokhoven, J. Phys. Conf. Ser., 2013, 430, Art. n. 012028.

25 A. L. Bugaev, O. A. Usoltsev, A. A. Guda, K. A. Lomachenko, M. Brunelli, E. Groppo, R. Pellegrini, A. V. Soldatov and J. van Bokhoven, Faraday Discuss., 2020, DOI: 10.1039/c9fd00139e.

26 A. L. Bugaev, A. A. Guda, K. A. Lomachenko, V. V. Shapovalov, A. Lazzarini, J. G. Vitillo, L. A. Bugaev, E. Groppo, R. Pellegrini, A. V. Soldatov, J. A. van Bokhoven and C. Lamberti, J. Phys. Chem. C, 2017, 121, 1820218213.

27 C. Langhammer, V. P. Zhdanov, I. Zoric and B. Kasemo, Chem. Phys. Lett., 2010, 488, 62-66.

28 C. Wadell, T. Pingel, E. Olsson, I. Zoric, V. P. Zhdanov and C. Langhammer, Chem. Phys. Lett., 2014, 603, 7581.

29 A. L. Bugaev, A. A. Guda, K. A. Lomachenko, V. V. Srabionyan, L. A. Bugaev, A. V. Soldatov, C. Lamberti, V. P. Dmitriev and J. A. van Bokhoven, J. Phys. Chem. C, 2014, 118, 10416-10423.

30 T. B. Flanagan and W. A. Oates, Ann. Rev. Mater. Sci., 1991, 21, 269-304.

31 B. Ingham, M. F. Toney, S. C. Hendy, T. Cox, D. D. Fong, J. A. Eastman, P. H. Fuoss, K. J. Stevens, A. Lassesson and S. Brown, Phys. Rev. B, 2008, 78, Art. n. 245408.

32 C. Langhammer, E. M. Larsson, B. Kasemo and I. Zoric, Nano Lett., 2010, 10, 3529-3538.

33 A. Kawasaki, S. Itoh, K. Shima and T. Yamazaki, Mater. Sci. Eng. A, 2012, 551, 231-235. 




